\title{
AVALIAÇÃO CLÍNICA E HISTOLÓGICA DAS REAÇÕES TECIDUAIS PRODUZIDAS POR DIFERENTES IMPLANTES DA ABRAÇADEIRA AUTOESTÁTICA DE NÁILON EM RATOS WISTAR
}

\author{
Clinical and histological evaluation of the tissue reactions produced by different \\ implants of nylon cable tie in Wistar rats
}

Ivan Felismino Charas Santos ${ }^{1}$, Brayan Sayed Lopez Castañeda, Nathalia N Rodríguez, José Ivaldo de Siqueira Silva Júnior, Gustavo Manea Ferreira, Bruna Martins Silva, Louise Tolffo Loibl

${ }^{1}$ Universidade Estadual Paulista. faculdade de Medicina Veterinária e Zootecnia, Botucatu

*Autor para correspondência: ivansantos7@hotmail.com

RESUMO: O objetivo do trabalho foi avaliar clinicamente ou macroscópica e histologicamente as reações teciduais produzidas pelo implante da abraçadeira autoestática de náilon transparente e colorida em ratos Wistar. Foram utilizados 48 ratos Wistar hígidos machos, com idade de 16 semanas e massa corpórea entre 350 e 450 gramas. Os animais foram alocados em dois grupos de 24 animais: Grupo 1 - ratos submetidos ao implante do fio de sutura náilon cirúrgico monofilamentar (Grupo Controle); Grupo 2 - ratos submetidos ao implante de fragmento da abraçadeira autoestática de náilon transparente e colorida (Grupo Experimental). As implantações no grupo controle foram realizadas com $5 \mathrm{~mm}$ de fio de sutura náilon cirúrgico monofilamentar entre o músculo carnoso e paravertebral esquerdo; e no grupo experimental foram implantadas $5 \mathrm{~mm}$ de fragmento da abraçadeira autoestática de náilon transparente e colorida, na mesma região em lados opostos e equidistantes da coluna vertebral. Oito ratos de cada grupo foram submetidos à eutanásia para realização da biopsia excisional dos implantes para posterior exame histológico em três momentos: sétimo dia, $15^{\circ}$ dia e $90^{\circ}$ dia após a implantação. A avaliação de infecção e/ou inflamação foi realizada a cada 24 horas. Lesões circunscritas multifocal ao redor dos três implantes foram observadas em $46,7 \%$ dos ratos, entre o primeiro e sétimo dia após as implantações. Reação inflamatória aguda esteve ausente em todos os grupos nos momentos avaliados. Reação inflamatória crônica foi observada no grupo do fio de sutura e das abraçadeiras em todos os momentos de avaliação, excetuando ao sétimo dia após a implantação no grupo das abraçadeiras autoestáticas transparentes. Reação inflamatória mista foi observada no grupo do fio de sutura e das abraçadeiras ao sétimo e $15^{\circ}$ dia. Os implantes do fio de sutura náilon cirúrgico monofilamentoso (Grupo Controle), das abraçadeiras autoestáticas de náilon transparente e colorida (Grupo Experimental) induziram reações clínicas ou macroscópicas e histológicas similares em ratos Wistar num período de 90 dias.

Palavras-chave: cirurgia; histologia; lacre; macroscopia; pequenos animais.

ABSTRACT: the aim of this study was to evaluate clinically and histological the tissue reactions produced by the implantation of the nylon cable tie transparent and colored in Wistar rats. Wistar male Wistar rats, aged 16 weeks, and weight between 350 and 450 grams were used. The rats were allocated in two groups of 24 animals: Group 1 - rats submitted to the implantation of the monofilament surgical nylon suture (Control Group); Group 2 - rats submitted to the implant of fragment of the transparent and colored nylon cable tie (Experimental Group). The implants of the animals of control group were performed with $5 \mathrm{~mm}$ of nylon suture monofilamentar 
between the carnosus and left paravertebral muscle; and $5 \mathrm{~mm}$ fragment were implanted in animal of experimental group of the transparent and colored nylon cable tie in the same region on opposite sides and equidistant from the spine. Eight rats from each group underwent euthanasia to perform the excisional biopsy of the implants for posterior histological examination in three moments: seventh day, $15^{\text {th }}$ day and $90^{\text {th }}$ day after implantation. Infection and / or inflammation evaluation was performed every 24 hours. Multifocal circumscribed lesions around the three implants were observed in $46.7 \%$ of the rats, between the first and seventh day after implantation. Acute inflammatory reaction was absent in all groups at the moments evaluated. Chronic inflammatory reaction was observed in the suture group and the clamps at all moments of evaluation except on the seventh day after the implantation in the group of transparent nylon cable tie. Mixed inflammatory reaction was observed in the suture group and the clamp bands on the seventh and $15^{\text {th }}$ day. The implants of monofilament surgical nylon suture (Control Group), transparent and colored nylon cable tie (Experimental Group) showed similar macroscopic (clinical) and histological reactions in Wistar rats in a period of 90 days.

Keywords: cable tie; histology; macroscopy; small animals; surgery. 


\section{INTRODUÇÃO}

Nas últimas décadas, as pesquisas na área da Medicina busca a produção de materiais de sutura de menor custo, maior resistência à tração, facilidade de esterilização e com reação tecidual mínima (Medeiros et al., 2016).

O processo inflamatório pode ser verificado ao se utilizar materiais de sutura implantados no organismo, e o mesmo pode durar entre dois a sete dias (Barros et al., 2011), e o grau de intensidade inflamatória dependerá da biocompatibilidade dos materiais utilizados (Barros et al., 2011; Kumar et al., 2013).

Dentro desse contexto, as abraçadeiras autoestáticas de náilon, são dispositivos produzidos à base de poliamida 6.6, a mesma composição presente no fio de náilon cirúrgico (Miranda et al., 2006; Silva et al., 2009). As mesmas apresentam formato de tira com diferentes comprimentos e colorações, são providas de sistema de trava sem retorno proporcionando maior segurança nas ligaduras vasculares, podem ser esterilizadas na autoclave a $121^{\circ} \mathrm{C}$ durante 40 minutos sem que ocorra redução da força tênsil (Miranda et al., 2006; Silva et al., 2009).

$\mathrm{Na}$ Medicina Veterinária foram utilizadas na ligadura do complexo arteriovenoso ovariano e uterino de cadelas (Barros et al., 2009; Lima et al., 2010), de gatas (Oliveira, 2006; Costa Neto et al., 2009) e de éguas (Silva et al., 2007; Rabelo, 2008); na ligadura do plexo vascular testicular de equinos (Silva et al., 2006; Finger et al., 2011) e de bovinos (Silva et al., 2009); na ligadura do ducto deferente em cães (Santos et al., 2012); e na ligadura do plexo vascular esplênico, da artéria gastroepiplóica e gástrica, e das veias do omento (Santos et al., 2017). Os autores citados anteriormente constataram facilidade na manipulação; redução do tempo do procedimento cirúrgico, anestésico, e dos custos.
Em procedimentos ortopédicos da rotina veterinária, foram utilizadas como método alternativo na redução e imobilização de fratura de ossos longos em associação com pinos intramedulares e placas ortopédicas (Miranda et al., 2006), na estabilização de fratura de maxila em cães (Sanches et al., 2010) e em fratura de mandíbula em gatos (Cunha et al., 2010).

Cunha et al. (2010), avaliaram radiograficamente o uso das abraçadeiras autoestáticas de náilon transparentes como técnica alternativa de fixação óssea em fraturas de sínfise mandibular em seis gatos. Os mesmos autores observaram menor reabsorção óssea nos gatos submetidos à cerclagem mandibular com as abraçadeiras autoestáticas de náilon em relação os gatos submetidos à cerclagem mandibular com o fio de aço, 15 dias após o procedimento cirúrgico.

Brandão et al. (2013) estudaram e compararam a biocompatibilidade das abraçadeiras autoestáticas de náilon transparente e de fio aço na cerclagem femoral de 21 coelhos e 15 ratos hígidos. Durante 150 dias de avaliação pós-implantação não foi observada alterações clinicas da função locomotora, macroscópicas e microscópicas.

Hoglund et al. (2011) utilizaram um dispositivo de polidioxanona com mesmo mecanismo de trava da abraçadeira autoestática de náilon para avaliação da oclusão dos vasos dos pedículos ovarianos e renais de porcos, sendo observada, microscopicamente, a oclusão dos vasos dos pedículos, hemostasia e adequado ajuste tecidual.

Visto que somente a abraçadeira autoestática de náilon transparente é utilizada em procedimentos cirúrgicos, além de existir escassez de estudos comparativos sobre as reações teciduais produzidas pelas abraçadeiras autoestáticas de náilon transparentes e coloridas, o objetivo do trabalho é avaliar clinicamente ou macros-copicamente e 
avaliar clinicamente ou macroscopicamente e histologicamente as reações teciduais produzidas pelo implante da abraçadeira autoestática de náilon transparente e colorida em ratos Wistar.

\section{MATERIAL E MÉTODOS}

Animais e ambiente de experimentação

Foram utilizados 48 ratos hígidos da espécie Rattus novergicus, linhagem Wistar heterogenéticos, machos não submetidos ao procedimento de contracepção, com idade de 16 semanas, e massa corpórea entre 350 e 450 gramas $(400 \pm 50$ gramas $)$, provenientes do Biotério Central da UNESP, campus de Botucatu, São Paulo. Os mesmos foram alocados individualmente em caixas plásticas forradas com maravalha e identificadas, e receberam água e ração comercial para ratos (Presence ${ }^{\circledR}$ ) ad libitum. O ambiente foi climatizado com temperatura de $22-25^{\circ} \mathrm{C}$ e umidade entre $40-60 \%$, e controle de luz com ciclos de 12 horas claro/escuro. As caixas foram limpas a cada 48 horas (Neves et al., 2013). O período de adaptação ao ambiente experimental foi de 30 dias.

Os animais foram alocados, aleatoriamente, utilizando o programa Randomizer $^{\circledR}$, em dois grupos de 24 animais: Grupo 1 - ratos submetidos ao implante do fio de sutura náilon cirúrgico monofilamentar (Grupo Controle); Grupo 2 - ratos submetidos ao implante de fragmento da abraçadeira autoestática de náilon transparente e colorida (Grupo Experimental).

\section{Procedimento experimental}

Após os ratos serem submetidos à anestesia com associação de cloridrato de xilazina $(10 \mathrm{mg} / \mathrm{kg})$ e cloridrato de cetamina $(75 \mathrm{mg} / \mathrm{kg}$ ) por via intraperitoneal (Neves et al., 2013), os mesmos foram colocados em decúbito ventral, as regiões cervicais e paravertebrais foram tricomizadas e preparadas para antissepsia com digliconato de clorexidina $(0,5 \%)$.

Segmento de $5 \mathrm{~mm}$ de fio de sutura náilon cirúrgico monofilamentar Shalon ${ }^{\circledR}$ 3-0 foi implantado entre o músculo carnoso e paravertebral esquerdo, com o auxílio da agulha curva incorporada ao fio. Fragmentos de $5 \mathrm{~mm}$ (0,015 gramas) da abraçadeira autoestática de náilon transparente e colorida foram implantados na mesma região em lados opostos e equidistantes da coluna vertebral (Figura 1). Previamente à implantação, as abraçadeiras foram esterilizadas na autoclave a $121^{\circ} \mathrm{C}$ durante 30 minutos.

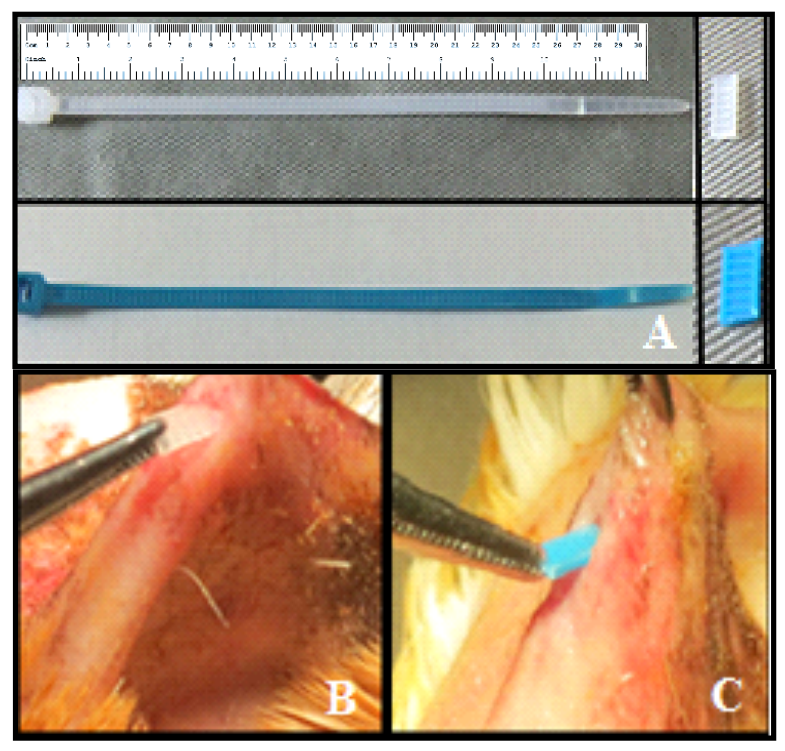

Figura 1 - Imagem fotográfica das abraçadeiras autoestática de nailon transparente e colorida (azul) (comprimento - $381 \mathrm{~mm}$; largura - 4,9 mm; sistema de tração mínima - 22,6 kg; tensão mínima - 54,4 kgf) e fragmentos de $5 \mathrm{~mm}$ das mesmas (A). Momento da implantação dos fragmentos das abraçadeiras autoestáticas de nailon transparente (A) e colorida (C) entre o músculo carnoso e paravertebral.

A dermorrafia foi realizada com fio de náilon cirúrgico monofilamentar Shalon ${ }^{\circledR} 4-0$, com padrão de sutura interrompida simples. O tratamento local foi realizado diariamente com solução salina $(0,9 \%)$ e pontos de sutura foram removidos três dias após a implantação.

Oito ratos de cada grupo foram submetidos à eutanásia com tiopental sódico $(120 \mathrm{mg} / \mathrm{kg})$ associado com 
lidocaína sem vasoconstritor $(7 \mathrm{mg} / \mathrm{kg})$ por via intraperitoneal (Neves et al., 2013), para a realização biopsia excisional dos implantes e posterior exame histológico, em três momentos distintos: sétimo dia, $15^{\circ}$ dia e $90^{\circ}$ dia após a implantação. Os locais da implantação e tecido circunvizinho (10 $\mathrm{mm}$ ) foram removidos e imediatamente colocados em formol tamponado (10\%). Após a fixação, foram realizados cortes transversais de tecido, contendo os implantes no centro e tecido de cada lado do mesmo. Os implantes foram removidos e as peças foram submetidas às técnicas de coloração de rotina de hematoxilina-eosina para avaliação histológica.

Assim, realizou-se a avaliação da intensidade do infiltrado inflamatório pela presença de células da reação inflamatória polimorfonucleares e mononucleares; e células gigantes multinucleadas, e pelas características histológicas. A leitura das lâminas foi realizada no microscópio óptico com lente aumento 10, dividido em 100 partes e fator de conversão de 0,0081, com lâmina micrométrica de $1 \mathrm{~mm}$ com escala de 0,01 mm.

A avaliação clínica ou macroscópica foi realizada a cada 24 horas verificando a presença de infecção e/ou inflamação.

\section{Análise estatística}

O exame histológico foi realizado seguindo um escore pré-definido para: infiltrado inflamatório, infiltrado de fibroblastos, angiogênese, presença de tecido de granulação e conjuntivo e infiltrado hemorrágico - ausente $[0 \%$ de preenchimento na lâmina, (-)], discreto [até $33 \%$ de preenchimento na lâmina, $(+)]$ moderado $[33-67 \%$ de preenchimento na lâmina, (++)] e acentuado $[67-100 \%$ de preenchimento na lâmina, (+++)] (Rstudio Team, 2016).

A avaliação clínica ou macroscópica foi realizada seguindo outro escore pré-definido para: presença de pus e/ou edema inflamatório ausente $[0 \%,(-)]$ e presente $[100 \%,(+)]$ (Rstudio Team, 2016).

As variáveis de ambas as avaliações foram realizadas por meio de testes estatísticos não-paramétricos (análise qualitativa). Para a análise entre os materiais no mesmo tempo experimental, foi utilizado 0 teste Kruskal-Wallis com pós-teste de Dunn. As comparações entre tempos diferentes de um mesmo material foram realizadas pelo teste Wilcoxon. Todos os testes foram realizados com nível de significância igual a 5\% utilizando o programa estatístico BioEstat 5.0

\section{RESULTADOS}

A temperatura corpórea mantevese dentro dos padrões fisiológicos normais da espécie, variando entre $36,2^{\circ} \mathrm{C}$ e $37,1^{\circ} \mathrm{C}\left(36,7 \pm 0,5^{\circ} \mathrm{C}\right)$. A massa corpórea diminui entre o primeiro (400 \pm 50 gramas) e segundo dia (370 \pm 10 gramas) após as implantações, e aumento a partir do terceiro dia após as implantações (425 \pm 10 gramas).

Não foi observado nenhum óbito e nem sinais clínicos de infecção em todos os animais de ambos os grupos.

\section{Avaliação clinica ou macroscópica}

Em $46,7 \%$ dos ratos do grupo controle e do grupo experimental, foi observado lesões circunscritas do tipo pápula, de aproximadamente $1 \mathrm{~mm}$ de diâmetro, com distribuição multifocal ao redor dos materiais implantados, entre o primeiro e sétimo dia após as implantações.

\section{Avaliação do infiltrado inflamatório}

A variação do infiltrado inflamatório dos animais do grupo controle e do grupo experimental estão apresentados na figura 2.

Em ambos os grupos foi observado um infiltrado inflamatório discreto, caracterizado por até $33 \%$ de preenchimento na lâmina de células de reação inflamatória (polimorfonucleares 
e mononucleares) e de tecido conjuntivo em todos os momentos avaliados, sendo abraçadeira autoestática colorida 15 dias após as implantações.

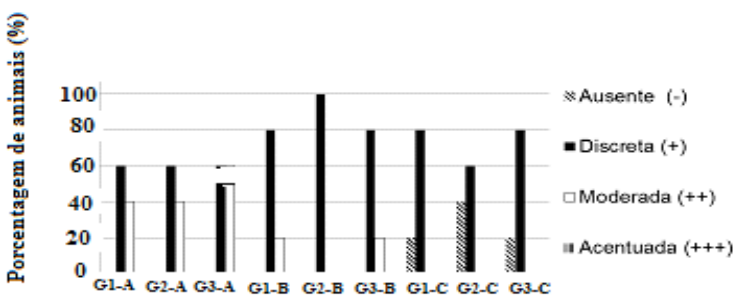

Figura 2 - Gráfico da intensidade do infiltrado inflamatório dos grupos das abraçadeiras autoestática de náilon transparente (G1) e colorida (G2) e do fio de sutura náilon cirúrgico (G3), ao sétimo dia $(A), 15^{\circ}$ dia (B) e $90^{\circ}$ dia (C) após as implantações.

A intensidade inflamatória moderada foi caracterizada por 33 $67 \%$ de preenchimento na lâmina de células de reação inflamatória polimorfonucleares e mononucleares e tecido conjuntivo em ambos os grupos no sétimo dia após as implantações e ausente nos implantes das abraçadeiras autoestáticas de náilon ao $15^{\circ}$ dia após as implantações. A mesma intensidade inflamatória esteve ausente em todos os grupos 90 dias após as implantações.

O infiltrado inflamatório acentuado não foi observado em nenhum dos animais de ambos os grupos nos momentos avaliados. Por outro lado, o infiltrado inflamatório esteve ausente nos animais do grupo controle e do grupo experimental no $90^{\circ}$ dia após as infiltrações.

\section{Avaliação histológica}

Momento de avaliação - sete dias após a implantação

Grupo controle. Os implantes do
grupo controle apresentaram
características histológicas similares dos implantes da abraçadeira autoestática de náilon colorida, com a presença de neutrófilos isolados, macrófagos, células gigantes, proliferação fibroblástica discreta e neovascularização (Figura 3).

Grupo experimental. Os implantes da abraçadeira autoestática de náilon transparente foram caracterizados pela presença de neutrófilos, focos hemorrágicos, fibroblastos, escasso tecido de granulação e conjuntivo (Figura 4).

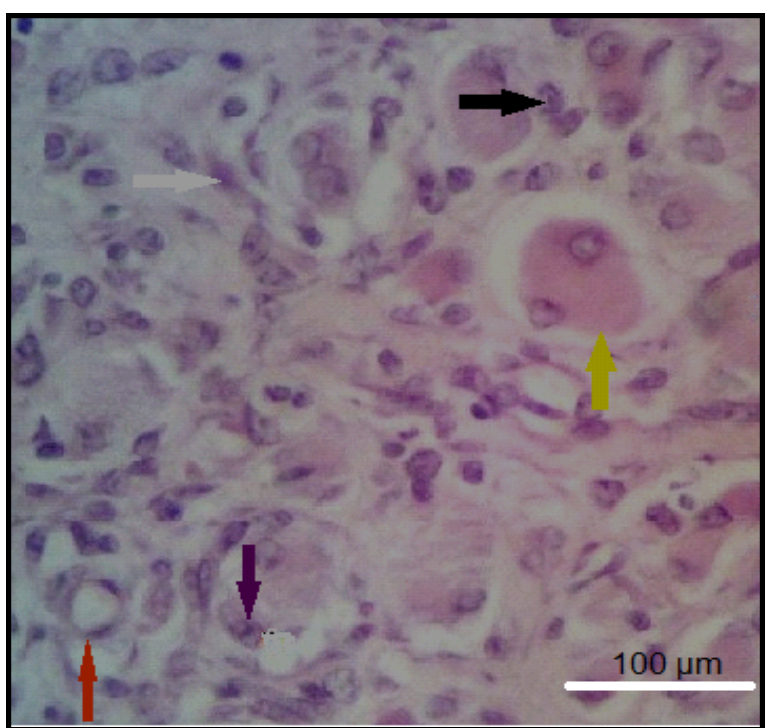

Figura 3 - Fotomicrografia do exame histológico dos implantes das abraçadeiras autoestáticas de náilon coloridas, sete dias após as implantações, ilustrando presença de neutrófilos (seta preta), células gigantes (seta amarela), macrófagos (seta roxa), fibroblastos (seta branca), tecido de granulação (seta verde), neovascularização (seta laranja), hemorragia (seta vermelha) e tecido conjuntivo (seta azul) (HE. 40x).

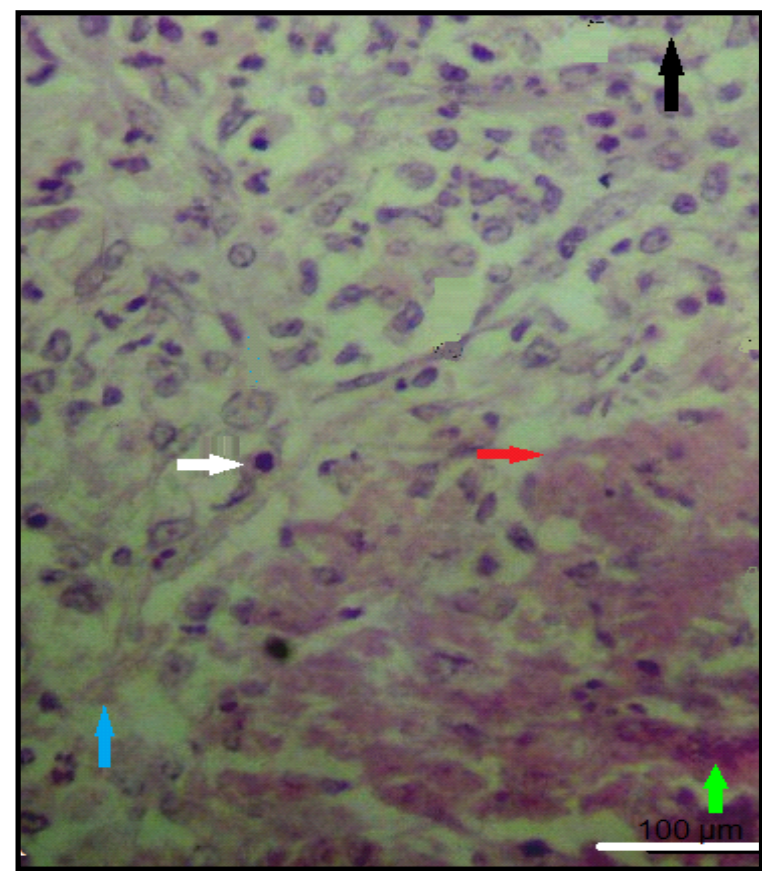

Figura 4 - Fotomicrografia do exame histológico dos implantes das abraçadeiras autoestáticas de náilon transparente, sete dias após as implantações, ilustrando presença de neutrófilos (seta preta), fibroblastos (seta branca), tecido de granulação (seta verde), hemorragia (seta vermelha) e tecido conjuntivo (seta azul) (HE. 10x) [Barra: $100 \mu \mathrm{m}$ ]. 
Momento de avaliação - 15 dias após a implantação

Grupo controle. Os implantes do fio de sutura náilon cirúrgico monofilamentar e os implantes da abraçadeira autoestática de náilon colorida apresentaram características histológicas similares com a presença de escassos neutrófilos e eosinófilos, proliferação fibroblástica moderada e células gigantes (Figura 5).

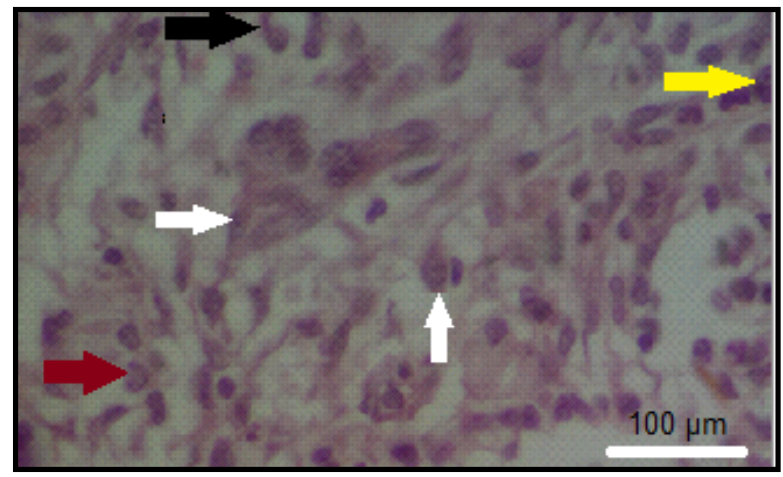

Figura $\mathbf{5}$ - Fotomicrografia do exame histológico dos implantes da abraçadeira autoestática de náilon colorida, 15 dias após as implantações, ilustrando neutrófilos (seta preta), células gigantes (seta amarela), macrófagos, fibroblastos (seta branca), eosinófilos (seta marrom) (HE. 40x).

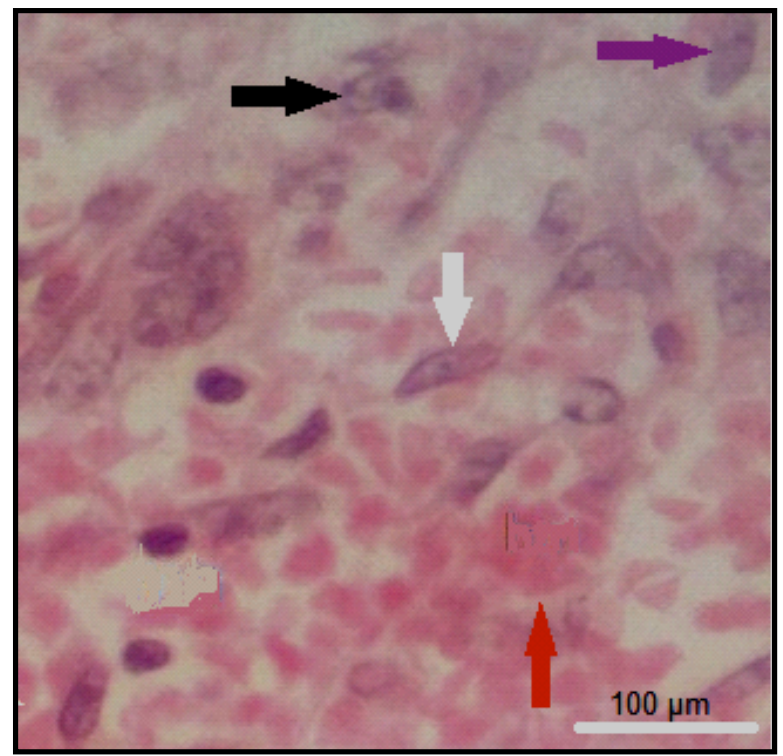

Figura 6 - Fotomicrografia do exame histológico dos implantes das abraçadeiras autoestáticas de náilon transparente, 15 dias após as implantações, ilustrando neutrófilos (seta preta), células gigantes (seta amarela), fibroblastos (seta branca) e hemorragia (seta vermelha)(HE. 40x).
Momento de avaliação - 90 dias após a implantação

Os implantes do fio de sutura náilon cirúrgico monofilamentar (grupo controle) e das abraçadeiras autoestáticas de náilon transparente e coloridas (grupo experimental) apresentaram características histológicas similares, ilustrando uma regressão acentuada da reação inflamatória, ausência de neovascularização e de proliferação fibroblástica, presença de escassos linfócitos e material fibroso (Figura 7).

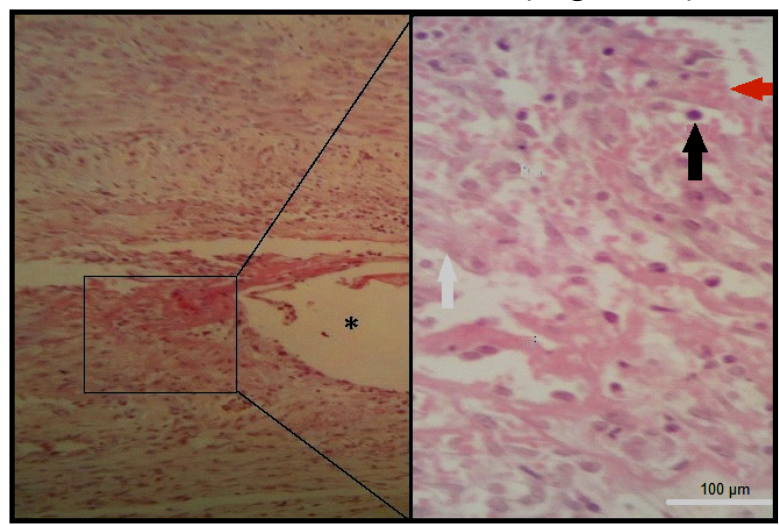

Figura 7 - Fotomicrografia do exame histológico do implante da abraçadeira autoestática de náilon colorida, noventa dias após as implantações, ilustrando espaço vazio que era ocupado pelo segmento da abraçadeira $\left({ }^{*}\right)$, foco hemorrágico (seta vermelha), linfócito (seta preta) e material fibroso (seta branca) (HE. 10x, 40x).

\section{DISCUSSÃO}

$O$ uso das abraçadeiras
autoestáticas de náilon em procedimentos cirúrgicos na Medicina Veterinária é polêmico devido à utilização de material não cirúrgico, e desse modo, interpretado como descaso com os animais. Por outro lado, existem citações na literatura em relação à utilização das abraçadeiras em procedimentos cirúrgicos em pacientes humanos (Schimidt e Davis, 1981; Chávez-Cartaya et al., 1992; Sorbello et al., 1999), e em animais (Silva et al., 2006; Rabelo et al., 2008; Silva et al., 2009; Barros et al., 2009; Costa Neto et al., 2009; Sanches et al., 2010; Finger et al., 2011; Santos et al., 2012; Santos et 
al., 2017), e sem evidência de efeitos colaterais. Segundo Marujo et al. (2012), a esterilização mal realizada das abraçadeiras e a técnica cirúrgica errônea são os principais fatores associados aos principais problemas citados pela literatura em relação ao uso das abraçadeiras na rotina cirúrgica (Werner et al., 1992; Macedo et al., 2012; Mesquita et al., 2015; Bregadioli et al., 2017). Desse modo, o presente trabalho se justificou pela praticidade no uso, segurança nas ligaduras vasculares e biocompatibilidade tecidual (Schimidt e Davis,1981; Chávez-Cartaya et al., 1992; Sorbello et al., 1999; Miranda et al., 2006; Oliveira et al., 2006; Silva et al., 2006; Silva et al., 2007; Barros et al., 2009; Costa Neto et al., 2009; Silva et al., 2009; Santos et al., 2012; Marujo et al., 2012).

Costa Neto e colaboradores (2014) compararam a biocompatibilidade entre a abraçadeira autoestática de náilon transparente e fio de náilon cirúrgico monofilamentar, por meio da avaliação histopatológica, em Rattus norvegicus. Os autores anteriormente citados não observaram diferenças significativas na evolução da resposta inflamatória entre a abraçadeira autoestática de náilon transparente e o fio de náilon cirúrgico monofilamentar, similar ao presente trabalho.

A exclusividade de uso das abraçadeiras autoestáticas de náilon transparentes nos procedimentos cirúrgicos em pacientes humanos e em animais, em detrimento às coloridas, pode estar relacionada com a ausência de vestígios de tintas ou vernizes. As tintas e vernizes podem possuir pigmentos a base de cromatos de chumbo e cádmio, que dependendo da quantidade e tempo de contato podem ser prejudiciais ao organismo. Porém, em nenhum momento foi referenciado a presença desses tipos de metais nas abraçadeiras autoestáticas de náilon coloridas.
No estudo do fio de sutura náilon cirúrgico monofilamentar (grupo controle) e das abraçadeiras autoestáticas de náilon transparente e coloridas (grupo experimental) observou-se uma diminuição da massa corpórea dos animais nos dois primeiros dias após as implantações dos materiais, e um aumento a partir do terceiro dia. Essa variação poderá estar relacionada com o estresse cirúrgico e processo inflamatório pós-operatório. Durante 0 processo inflamatório ocorre produção de citocinas inflamatórias, interleucinas 1 e 6, e fator de necrose tumoral (TNF), e consequentemente as proteínas de fase aguda, que agem como mediadores da inflamação e da imunidade (Paschoalini et al., 2005). Níveis elevados de TNF podem influenciar na perda de peso, uma vez que estimula a produção de leptina, induzindo o organismo ao gasto energético e diminuição do consumo de alimentos (Paschoalini et al., 2005), porém, no presente trabalho não foi observada variação significativa da temperatura corpórea.

Sete dias após as implantações foram observadas reações tecidual do tipo alérgica ao redor de todos dos implantes do grupo controle e experimental, em $46,7 \%$ dos animais. A reação foi associada com a utilização do povidato de iodo, uma vez que após a suspensão do mesmo não foram observadas o mesmo tipo de reação local. O iodo no seu estado genérico não é alergênico, porém, foi relatado dermatite de contato alérgica com erupções cutâneas ou urticária em pacientes sensíveis ao iodo (Kerr e Krucik, 2013). Visto que a reação tecidual foi observada também nos implantes do fio de náilon cirúrgico monofilamentar (grupo controle), a probabilidade da reação alérgica estar associada as abraçadeiras autoestáticas de náilon foi nula.

$\mathrm{Na}$ avaliação macroscópica foi observada reação inflamatória discreta em todos os grupos durante todos os 
momentos avaliados, caracterizada por mínima quantidade de exsudato e hiperemia e ausência de aderência aos fragmentos, coerente com citado pela literatura (Costa Neto et al., 2014). De acordo com Pavanatti (2001), os resultados são indicativos da tolerabilidade do material implantado pelo tecido receptor.

Uma vez que as abraçadeiras autoestáticas de náilon são desenvolvidas com o mesmo material do fio de náilon - poliamida acredita-se que as reações inflamatórias teciduais sejam similares às do fio de náilon cirúrgico monofilamentar. Lima e et al. (2010) não observaram diferenças significativas com relação à incidência de neovascularização, formação de tecido de granulação e presença de infiltrado inflamatório entre a abraçadeira autoestática de náilon e fio de sutura náilon cirúrgico monofilamentar, 60 dias após o seu uso em pedículos ovarianos de cadelas hígidas.

No estudo, a avaliação histológica dos materiais foi realizada em três momentos distintos: sete, 15 e 90 dias após as implantações, de acordo com a literatura (Bettes, 2003; Ribeiro et al., 2005; Matos, 2007).

Todos os implantes apresentaram uma reação inflamatória moderada no sétimo e $15^{\circ}$ dia após as implantações regredindo para uma reação discreta no $90^{\circ}$ dia, similar com o relatado pela literatura (Costa Neto et al., 2014), e com reações teciduais produzidas pelo fio de pesca $100 \%$ poliamida e fio de náilon monofilamentar em ratos (Souza, 2001). Acredita-se que a similaridade da reação inflamatória observada entre os materiais testados no presente estudo esteve associada à mesma composição química das abraçadeiras autoestáticas de náilon e fio de náilon cirúrgico, a poliamida 6.6.

Os implantes das abraçadeiras autoestáticas de náilon colorida e do fio de sutura náilon cirúrgico monofilamentar induziram uma reação do tipo corpo estranho até o sétimo dia após as implantações, caracterizada pela presença de neutrófilos isolados, macrófagos e células gigantes, similar com o citado pela literatura (Sorbelo et al., 1999). Esta reação perdurou até ao $15^{\circ}$ dia após as implantações similar com o descrito na literatura (Bettes, 2003; Oliveira, 2006). Porém, os implantes das abraçadeiras autoestáticas de náilon colorida teve uma regressão acentuada da reação inflamatória a partir do oitavo dia, diferentemente da literatura que citou a presença de neutrófilos e de células gigantes ao redor dos implantes das abraçadeiras autoestáticas de náilon transparentes 45 dias (Barros et al., 2009).

A presença de fibroplasia e neovascularização associada ao aumento da reação inflamatória no sétimo e $15^{\circ}$ dia após as implantações, e diminuição da mesma no $90^{\circ}$ dia, nos implantes do grupo controle e experimental, sugeriu um processo inflamatório e processo de cicatrização fisiológica (Matos 2007; Puricelli et al., 2011). Segundo Puricelli e colaboradores (2011), a maior intensidade da resposta inflamatória é observada na fase de reconhecimento do agente agressor e regressão quando o agente é eliminado ou encapsulado.

\section{CONCLUSÃO}

No período de estudo de 90 dias, os implantes da abraçadeira autoestática de náilon transparente e colorida induzem reações teciduais histológicas similares em ratos Wistar e nenhum dos implantes induz reação tecidual clínica.

\section{NOTAS INFORMATIVAS}

A metodologia foi analisada pela Câmara de Ética em Experimentação Animal da Faculdade de Medicina Veterinária e Zootecnia (FMVZ) da Universidade 
Estadual Paulista (UNESP) - Botucatu, São Paulo (SP), com protocolo $\mathrm{n}^{\circ}$ 0137/2018.

\section{REFERÊNCIAS}

BARROS, B.J.; SANCHES, A.W.E; PACHALY, J.R. Utilização de abraçadeiras de náilon 6.6 (poliamida) como método de ligadura de pedículos ovarianos e coto uterino em ováriohisterectomia eletiva em cadelas (Canis familiaris). Arquivo de Ciência Veterinária e Zoologia da Unipar, Umuarama, v. 12, n. 1, p. 47-60. 2009.

BARROS, M.; GORGAL, R.; MACHADO, A.P. et al. Princípios básicos em cirurgia: Fios de sutura. Acta Médica portuguesa, v.12, n.4, pág. 1051-1056. 2011.

BETTES, P.S.L. Análise comparativa histológica e tensiométrica entre a cicatrização de feridas cutâneas tratadas com 0 adesivo octil-2cianocrilato e com sutura intradérmica em ratos. 2003. Curitiba, 144f. Tese (Doutorado em Clínica Cirúrgica), Universidade Federal do Paraná.

BRANDÃO, C.V.S.; ANTUNES, P.A.U.M.C.; ESTANISLAU, C.A. et al. Cinta de náilon como cerclagem óssea estudo experimental em coelhos e ratos. Semina Ciências Agrárias, v.34, n.6, p.2903-2914, 2013.

BREGADIOLI T.; FERRIGNO C.R.A.; FERREIRA M.P.; et al. Complicações relacionadas ao uso de abraçadeira de náilon como implante ortopédico. Revista CFMV, v.23, n.72, p.67-71, 2017.

CAMPBELL, J. R. E MARKS, A. Suture materials and suturing techniques. In: Practice, v.7, p.55-72. 1985.

CHÁVEZ-CARTAYA, R.; JIRÓNVARGAS, A.; PINTO, S. et al. Adjustable náilon ties for abdominal Wall closure.
The American Journal Of Surgery, v.163, p.609-612. 1992.

COSTA NETO, J. M.; LIMA, A.E.S.; ORIÁ, A.P. et al. Análise histopatológica das reações teciduais produzidas pelo implante de fio e de braçadeira de náilon. Enciclopédia Biosfera, Centro Científico Conhecer - Goiânia, v.10, n.18; p. 291, 2014.

COSTA-NETO, J. M.; TEIXEIRA, E. M.; FERREIRA FILHO, E. M. et al. Braçadeira de náilon para hemostasia preventiva na ovariosalpingohisterectomia em gatas. Revista Brasileira de Saúde e Produção Animal, v. 10, n. 3, p.615624, 2009.

CUNHA, M.G.M.C.M.; PIPPI, N.L.; SANTOS JUNIOR, E.B. et al. Cerclagem com abraçadeira de náilon ou de fio de aço no reparo de fraturas experimentais de sínfise mandibular em gatos. Acta Scientiae Veterinariae, v.38, n.4, p.363369, 2010.

FINGER, M.A.; DORNBUSCH, P.T.; BONFÁ A. et al. Comparação de duas técnicas de orquiectomia em equinos, empregadas no ensino da técnica cirúrgica veterinária. Archives of Veterinary Science, v.16, n.3, p.53-59, 2011.

HOGLUND, O.V.; HAGMAN, R.; OLSSON, K.; et al. A new resorbable device for ligation of blood vessels - A pilot study. Acta Veterinaria Scandinavica, v.53, n.47, 2011.

HOLLINGSWORTH. Abraçadeira de náilon "Easy -ty". [online], 2010. Disponível em: http://www.hollingsworth.com.br/abracad eiras.html Acesso em: 14 de abril de 2018.

KERR, M. E KRUCIK, G. 2012. lodine Allergy Healthline. Disponível em: http://www.healthline.com/health/allergie s/iodine. Acessado em: 17 de abril de 2018. 
KUMAR V.; KHAN A.A.; NAGARAJAN K. Animal models for the evaluation of wound healing activity. Internation Bulletin Drug Research, v.3, p.93-107, 2013.

LIMA, A. F. M.; LUNA, S. P. L.; RODRIGUES, M. M. P. et al Avaliação histológica e videolaparoscópica de ligaduras dos pedículos ovarianos realizados com mononáilon agulhado ou abraçadeiras auto-estáticas de náilon em cadelas submetidas

ovariossalpingohisterectomia pela técnica do Gancho. ARS Veterinária, v.26, n.2, p.66-70. 2010.

MACEDO A.S.; DALBO I.S.; QUADROS A.M.; et al. Complications associated with ovariohysterectomy using nylon tierap as a hemostatic method. Acta Scientiae Veterinariae, v. 21, p.176179, 2012.

MARUJO, R.B.; LUNA, S. P. L.; LIMA, A. F. M. et al. Abraçadeira autoestática de náilon na cirurgia veterinária: revisão de literatura. Nosso Clínico, v.96, p. 50 54. 2013.

MATOS, W. P. Estudo comparativo das reações teciduais produzidas pela abraçadeira de náilon e o fio de náilon cirúrgico implantados na musculatura de ratas. 2007. Salvador, 56f. Monografia (graduação). Escola de Medicina Veterinária Universidade Federal da Bahia.

MEDEIROS A.M.; ARAÚJO-FILHO I.; CARVALHO M.D.F. Fios de sutura. Journal of Surgical Clinical Research, v.7, p.274-286, 2016.

MESQUITA L.R.; RAHAL S.C.; MATSUBARA L.M.; et al. Bilateral hydronephrosis and hydroureter after ovariohysterectomy using nylon cable tie: a case report. Veterinarni Medicina, v.60, n.1, p.52-56, 2015.

MIRANDA, A. H.; DA SILVA, L. A. F.; TAVARES, G. A. et al. Abraçadeira de náilon: resistência à tração em testes físicos e seu emprego como cerclagem no fêmur de cães. Ciência Animal Brasileira, v. 7, n. 3, p. 299-307, 2006.

NEVES S.M.P.; ONG F.M.P; RODRIGUES L.D.; DOS SANTOS R.A.; FONTES R.S.; SANTANA R.O. Manual de Cuidados e Procedimentos com Animais de Laboratório do Biotério de Produção e Experimentação da FCFIQ/USP. Universidade de São Paulo Faculdade de Ciências Farmacêuticas Instituto de Química (FCF-IQ/USP), $217 p, 2013$.

OLIVEIRA, M. S. Utilização de abraçadeira de náilon para hemostasia preventiva na ovariosalpingohisterectomia em gatas. 2006. Salvador, 44f. Monografia (graduação). Universidade Federal da Bahia Escola de Medicina Veterinária.

PASCHOALINI, M.A. et al. Regulação do peso corporal. In: Seminário de interação sobre os aspectos morfofuncionais orais de clínica médica e de saúde pública. Universidade Federal de Santa Catarina, Brasil, p. 76, 2005.

PAVANATTI, S.L.; ZAVAGLIA, C.A.C.; BELANGERO, W.D.; et al. Estudo sobre a $\$ 3$ ocompatibilidade da polisulfona sob a forma de partículas e bastões. Acta Ortopédica Brasileira, v.9, n.3, p.11-18, 2001.

PURICELLI, E.; NÁCUL, A. M.; PONZONI, D.; CORSETTI, A.; et al. Implante intramuscular de polimetilmetacrilato (PMMA) 30\%, associado a veículo não-proteico: estudo experimental em ratos. Revista Brasileira de Cirurgia Plástica, v.26, n.3, p.385-389. 2011.

RABELO, R.E.; SILVA, L.A.F.; SANT'ANA, J.F.; et al. Uso de abraçadeira de poliamida para ovariectomia em éguas em posição quadrupedal. Acta Scientiae Veterinariae, v.36, n.2, p.119-125, 2008.

RIBEIRO, C. M. B.; JÚNIOR, V. A. S.; NETO, J. C. S et al. Estudo clínico e 
histopatológico da reação tecidual às suturas interna e externa dos fios monofilamentares de náilon e poliglecaprone 25 em ratos. Acta Cirúrgica Brasileira, v. 20, n.4, p.284291, 2005.

RSTUDIO TEAM. RStudio: Integrated Development for R. RStudio, Inc., Boston, MA. 2016.

SANCHES, A.R.; ROSA-JÚNIOR, A.S.; RAPPETI-PEDROZO, J.C.S. et al. Uso da abraçadeira de náilon na estabilização de fratura de maxila em cão: relato de caso. $\mathbf{2}^{\mathbf{a}}$ Mostra científica, XII ENPOS. 2010.

SANTOS, I.F.C.; CANDA, R.; AUGUSTO, L.; et al. Eficácia da abraçadeira e do fio de náilon na deferentectomia e laqueação dos ductos deferentes em cães adultos (Estudo comparativo). ARS Veterinária, v. 28, n. 2, p. 75-84, 2012.

SANTOS I.F.C.; POENTE, M.P.; BROMBINI, G.C. et al. Hemostasis Technique Using an Adjustable Nylon Tie in Dog with Splenic Hematoma and Lymphoid Hyperplasia Acta Scientiae Veterinariae, v. 44, n.1, p. 201, 2017.

SILVA, L.A.F.; COSTA, A.C.; SOARES, L.K.; et al. Orquiectomia em bovinos empregando abraçadeira de náilon na hemostasia preventiva: Efeito da estação do ano, método de contenção cirúrgica. Ciência Animal Brasileira, v. 10, n. 1, pág. 261-270. 2009.

SILVA, L.A.F.; FRANÇA, R.O.; VIEIRA, D.; et al. Emprego da abraçadeira de náilon, do categute e do emasculador na hemostasia preventiva de ovariectomia em éguas. Ciência Animal Brasileira, v. 8, n. 1, p.135-146, 2007.

SILVA, L.A.F.; FRANÇA, R.O.; VIEIRA, D.; et al. Emprego da abraçadeira de náilon na orquiectomia em equinos. Acta Scientiae Veterinariae, n. 34, p.261266, 2006.

SILVA, L.S. Aplicabilidade e reação tecidual dos fios de sutura. 2009.
Goiânia, 42f. Seminários Aplicados, Programa de Pós-Graduação em Ciência Animal. Universidade Federal de Goiás.

SORBELLO, A.A., GIUDUGLI, J.N.E.; ANDRETTO, R. Nova alternativa para ligadura em cirurgias vídeoendoscópicas ou convencionais, com emprego de fitas de náilon em estudo experimental. Revista Brasileira de Coloproctologia, v.19, n.1, p.24-26. 1999.

SOUZA, M. Aspectos morfológicos da cicatrização de feridas cirúrgicas da pele de ratos suturadas com diferentes tipos de fios de poliamida. 2001. São Paulo, 43f. Dissertação (Mestrado em Técnica Operatória e Cirurgia Experimental) - Escola Paulista de Medicina. Universidade Federal de São Paulo.

WERNER R.E.; STRAUGHAN A.J.; E VEZIN D. Nylon cable band reactions in ovariohysterectomized bitches. Journal of the American Veterinary Medical Association, v. 200, p.64-66, 2012. 